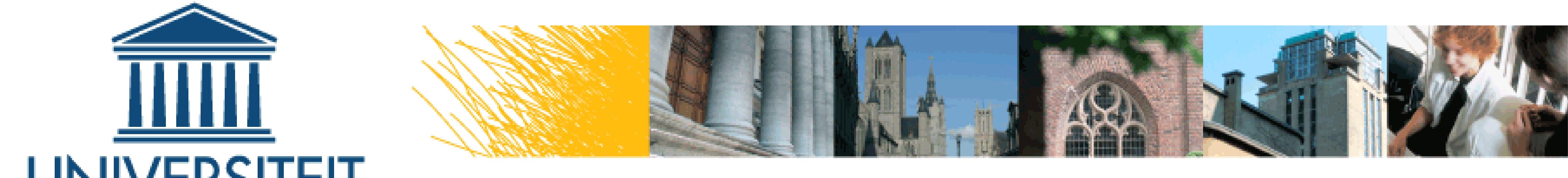
GENT

\title{
Is there a difference in visual search patterns between watching video clips of fencers on a computer screen or on a life-sized screen?
}

Department of Movement and Sports Sciences, Ghent University, Belgium

\section{Introduction}

To compare the visual attention of multiple subjects in a sports situation, an identical stimulus has to be presented, which is often only possible by using video stimuli. Therefore, reacting on video clips, projected on a large screen, seems to approach a real-life situation the most. Reacting while watching a projection screen implies that a Head-mounted Eye-tracking Device (HED) has to be used, implicating time consuming data analysis. When participants only have to watch the video, a Remote Eye-tracking Device (RED) can be used. With these devices, automated data analysis ensures less time loss. However, gaze behavior while watching videos on a computer screen might differ from gaze behavior when reacting on them on a life-sized projection screen. In current experiment gaze behavior of elite fencers was examined in three different conditions.

\section{Methods}

Participants. Thirteen elite fencers (five females, age $16.92 \pm 3.15$ ) were recruited to participate in this study. Test Film. Ten attacking and defensive movements, performed by three different expert fencers were presented as visual stimuli. Five defensive movies were used for analysis. Participants viewed these five videos three times in random order for each condition.

\section{Procedure.}

- Condition 1 (HEDmov), participants were standing in front of the projection screen $\left(2 \mathrm{~m} \times 3 \mathrm{~m}\right.$, visual angle $\left.38^{\circ}\right)$ and were instructed to react with an appropriate response, while eye movements were tracked with the portable eye tracker (HED $\mathrm{SMI}, 50 \mathrm{~Hz}$ ).

- Condition 2 (HEDseated), participants were seated $3 \mathrm{~m}$ in front of the projection screen and watched the 15 clips again while eye movements were recorded with the portable eye tracker.

- Condition 3 (REDseated), participants saw the same 15 clips sitting in front of a PC screen (22") while Eye movements were recorded with a Remote Eye tracking Device (RED - SMI, $120 \mathrm{~Hz}$ )

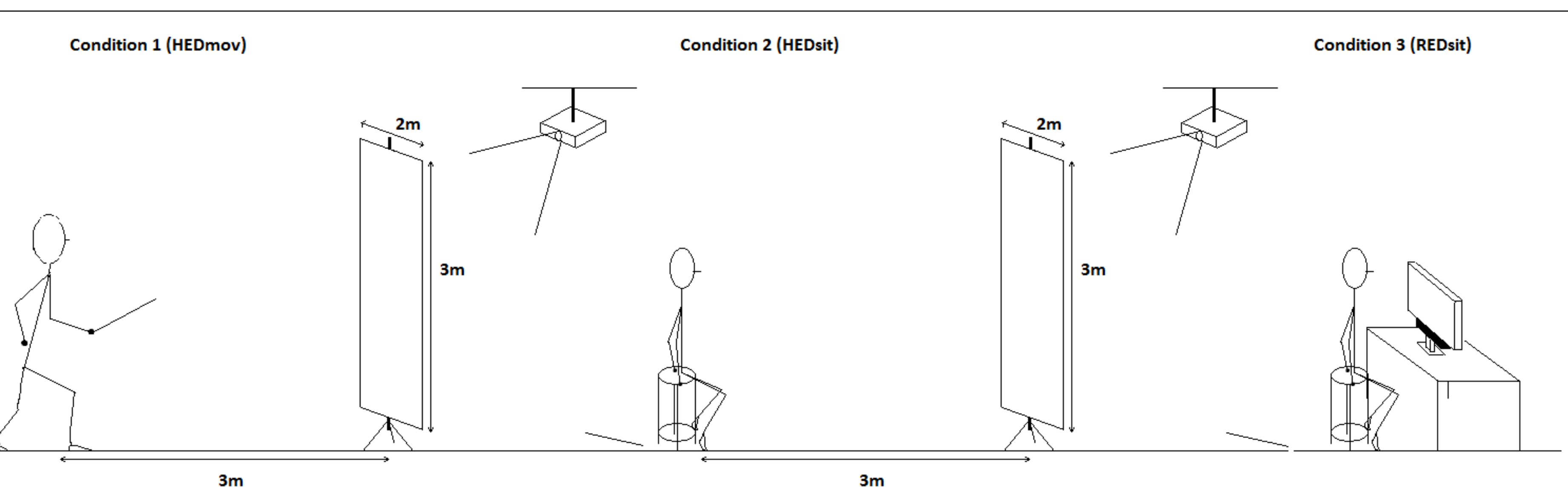

Figure 1. Experimental set-up for each condition.

Analysis. Twelve Areas Of Interest (AOI) [2] were chosen for frame-by-frame analysis in SMI BeGaze 3.2. with a spatial accuracy of $1^{\circ}$. Dwell time fixation detection for each $\mathrm{AOI}$ was measured. Confidence levels were set at $p \leq 0.05$.

- Dwell time for each AOI between conditions was explored.

- Reliability was measured for each movie, using an Intraclass correlation, and across all 15 trials.

- Similarity in eye movements between the three testing conditions was measured using a Pearson's Correlation Coefficient.
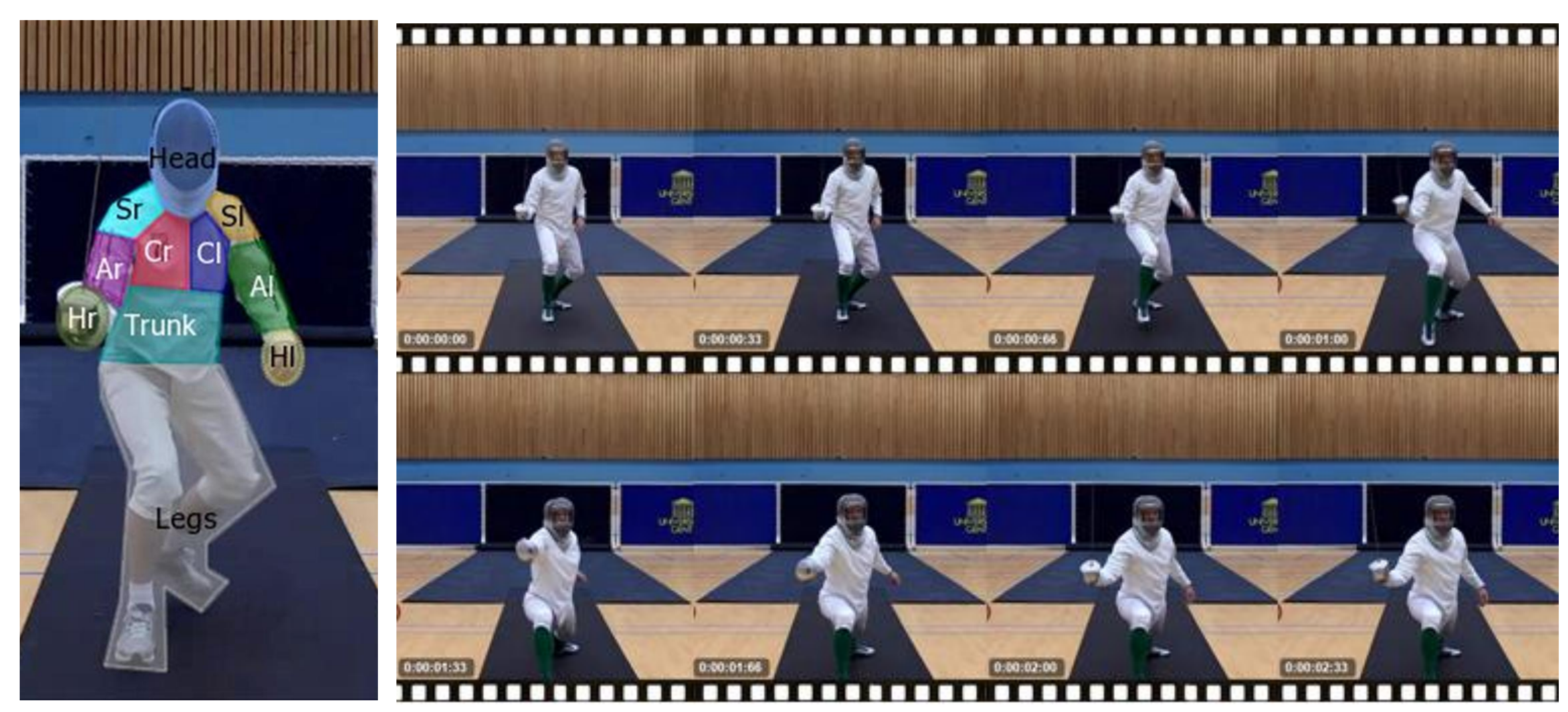

Figure 2. displays the 12 Areas Of Interest in the movie clips. Head, shoulder right (Sr), chest right (Cr), arm right (Ar), hand right ( $\mathrm{Hr})$, shoulder left (SI), chest left (Cl), arm left (Al), hand left $(H I)$, trunk, legs, and other (includes time when there was no gaze cursor present).
Corresponding author: linus.zeuwts@ugent.be

\section{Results}

- Head, chest right, hand right and trunk are most used (Figure 3)

- Participants tend to look more centrally, especially in REDseated:

$\Rightarrow$ Use of anchor-point

$\Rightarrow$ Smaller screen size

$\Rightarrow$ Countdown before each clip, centrally on the screen

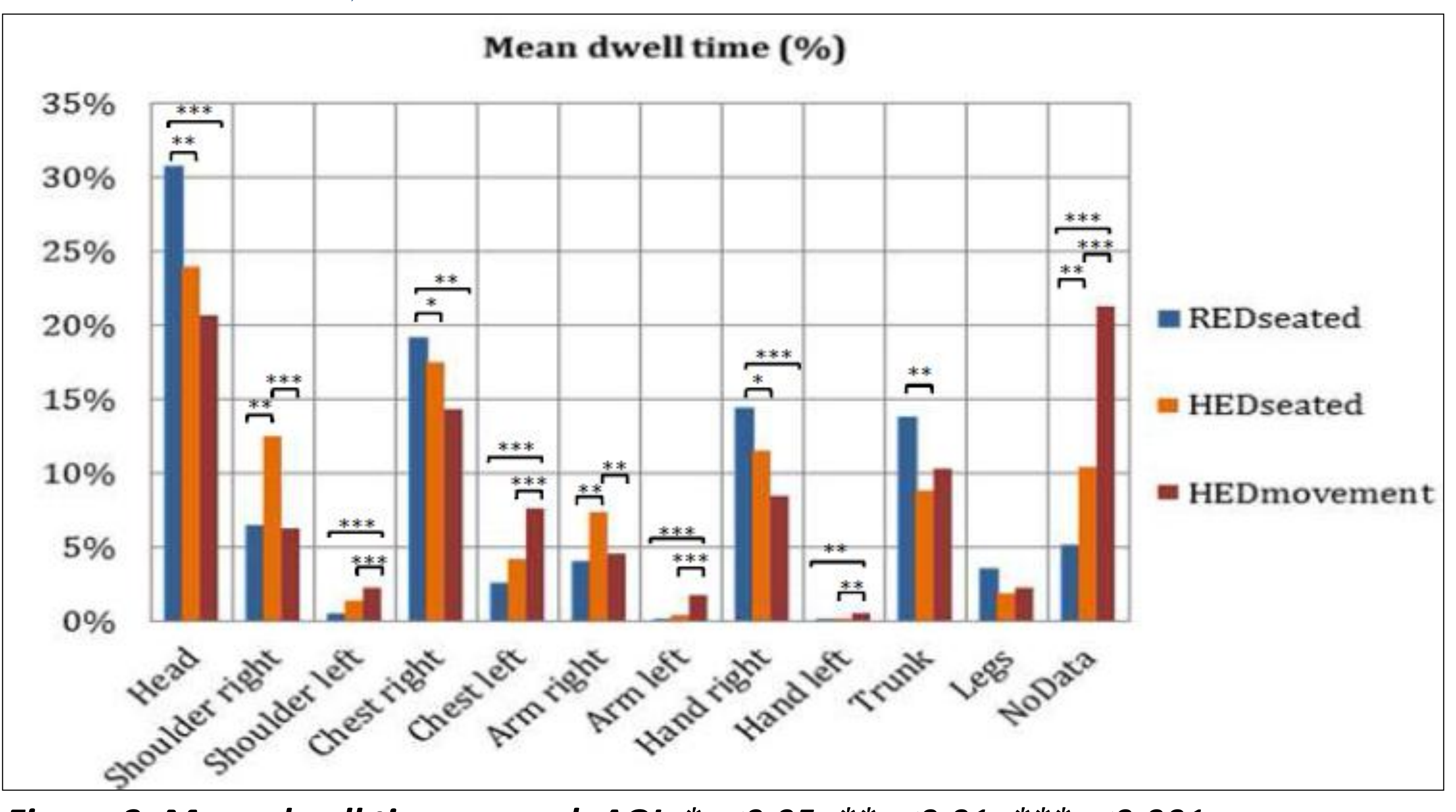

Figure 3. Mean dwell time on each AOI. ${ }^{*} p \leq 0.05,{ }^{* *} p \leq 0.01,{ }^{* * *} p \leq 0.001$

- Low Intraclass correlations in movies and across all trials (table 1)

$$
\begin{aligned}
& \Rightarrow \neq \text { visual search in the same movies } \\
& \text { Individual differences } \\
& \text { No consistent search across al movies }
\end{aligned}
$$

Table 1. ICC for each movie (three trials) and across all movies (15 trials) for each condition. All were significant at $p \leq 0.001$

\begin{tabular}{lllllll}
\hline \multicolumn{7}{c}{ Intraclass Correlation } \\
\hline Condition & Movie 1 & Movie 2 & Movie 3 & Movie 4 & Movie 5 & All Movies \\
REDsit & 0.429 & 0.450 & 0.452 & 0.461 & 0.473 & 0.455 \\
HEDsit & 0.440 & 0.312 & 0.282 & 0.434 & 0.183 & 0.332 \\
HEDmov & 0.431 & 0.454 & 0.300 & 0.502 & 0.371 & 0.409 \\
\hline
\end{tabular}

- Low correlations (table 2) between conditions indicate certain differences in visual search:

$$
\begin{aligned}
& \Rightarrow \text { Ventral and dorsal stream [3] } \\
& \text { Low consistency within conditions (table 1) } \\
& \text { Individual differences }
\end{aligned}
$$

Table 2. Correlations for dwell time between each condition. Pearson Correlations

REDseated-HEDseated REDseated-HEDmov

$0.241(p \leq 0.001)$ $0.229(p \leq 0.001)$

HEDseated-HEDmov $0.163(p \leq 0.001)$

\section{Implications:}

- Training should integrate vision for perception and vision for action.

- Experiments can't be simplified

Limitations:

- Dwell time alone was used

- Video clips were very short

- Due to safety and experimental control, no real life situation could be generated

- Visual angle of some AOls was similar to the visual accuracy of the eye tracker

\section{Conclusions}

Eye movements recorded with RED were different from visual behavior recorded with HED while seated or HED while executing real time responses. Although data loss in HEDmov was high, our findings partly jeopardizes the use of PC-based video clips for tactical training in sport $[1,3]$. Research should focus more on the effects of visual training with integration of vision for action.

\section{References}

1. Williams, A. M., Ward, P., Knowles, J. M., Smeeton, N. J. (2002). Anticipation skill in a real-world task: Measurement, training, and transfer in tennis. Journal of Experimental Psychology: Applied, 8(4), 259-270.

2. Hagemann, N., Schorer, J., Canal-Bruland, R., Lotz, S., Strauss, B. (2010). Visual perception in fencing: Do the eye movements of fencers represent their information pickup?, 72(8), 2204-2214.

3. Button, C., Dicks, M., Haines, R., Barker, R., Davids, K. (2011). Statistical modelling of gaze behaviour as categorical time series: what you should watch to save soccer penalties. Cognitive processing, 12(3), 235-44. 
